\title{
JUL 311264
}

\section{MASTER}

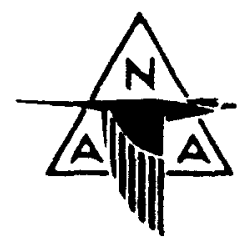

NAA-SR-1137 (PL.H)

COPY $2 \cdot 0$

35 PAGES

PHYSICS

\section{ABSOLUTE THERMAL NEUTRON DETERMINATION}

PART II:

ABSOLUTE BETA COUNTING

OF INDIUM FOILS

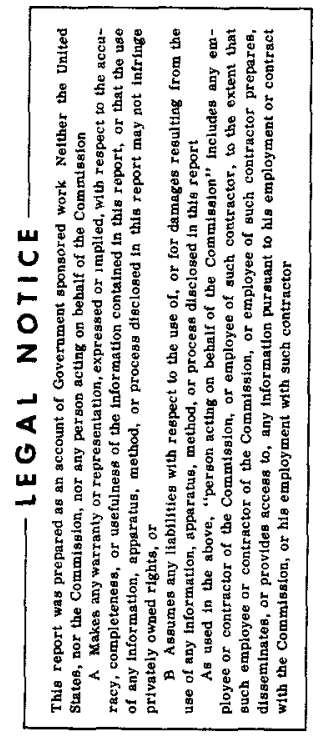

\author{
WRITTEN BY: \\ ROSCOE L. KOONTZ \\ MOSES A. GREENFIELD* \\ ALAN A. JARRETT \\ WORK DONE BY: \\ MOSES A. GREENFIELD \\ ALAN A. JARRETT \\ ROSCOE L. KOONTZ \\ JUANITA K. TAYLOR
}

NUCLEAR ENGINEERING AND MANUFACTURING

NORTH AMER ICAN AVIATION, INC.

P. O. BO 309

"Department ut Raclublogy

ISSUE DATE

OCTOBER 1, 1955

Medical Center

University of Californa at Los Angules 
-

6

1

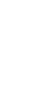

.

-




\section{DISCLAIMER}

This report was prepared as an account of work sponsored by an agency of the United States Government. Neither the United States Government nor any agency Thereof, nor any of their employees, makes any warranty, express or implied, or assumes any legal liability or responsibility for the accuracy, completeness, or usefulness of any information, apparatus, product, or process disclosed, or represents that its use would not infringe privately owned rights. Reference herein to any specific commercial product, process, or service by trade name, trademark, manufacturer, or otherwise does not necessarily constitute or imply its endorsement, recommendation, or favoring by the United States Government or any agency thereof. The views and opinions of authors expressed herein do not necessarily state or reflect those of the United States Government or any agency thereof. 


\section{DISCLAIMER}

Portions of this document may be illegible in electronic image products. Images are produced from the best available original document. 


\section{TABLE OF CONTENTS}

Page No.

Abstract . . . . . . . . . . . . . . . . . . 5

I. Introduction . . . . . . . . . . . . . . . . 47

II. Methods. . . . . . . . . . . . . . . . . 9

III. Materials . . . . . . . . . . . . . . . . . 10

VI. Instrumentation . . . . . . . . . . . . . . . . . 11

V. Experimental . . . . . . . . . . . . . . . 12

A. Irradiation Procedure . . . . . . . . . . 12

B. Counting Procedure . . . . . . . . . . . 12

C. Backscatter of the Support. . . . . . . . . 13

VI. Results . . . . . . . . . . . . . . . . . 13

VII. Discussion of Results . . . . . . . . . . . . . . . 14

VIII. Errors . . . . . . . . . . . . . . . . . 17

Appendices

A. Correction of Specific Activity Due to Neutron Effects . . . . . . . . . . . . . 27

B. Absolute Specific Activity of Indium Foils. . . . 30

References. . . . . . . . . . . . . . . . 35 


\section{LIST OF FIGURES}

Page No.

1. Evaporation Apparatus for Making $1 \mathrm{~cm}^{2}$ Indium Folls . . . 18

2. A $1 \mathrm{~cm}^{2}$ Indium Foil Evaporated on a Collodion Supporting Film and Mounting by Concentric Graphite Rings . . . . .

3. Modified Nuclear Measurement Corporation $2 \pi$ Proportional Counter. . . . . . . . . . . . . . . . . . . 20

4. Assembly Drawing of the Modified $2 \pi$ Counter . . . . . 21

5. Self-Absorption Correction Factor for Backless Indium Foils in a $2 \pi$ and Windowless Counter . . . . . . . . . . 22

6. Self-Absorption, Back Scattering, and Photon Contribution Correction Factor for Indium Foils Counted on Thick Silver Backing in a $2 \pi$ Windowless Counter. . . . . . . . . 23

7. Self-Absorption Correction Factor for Indium Folls Counted with an End Window GM Counter at $2.2 \mathrm{~cm}$. . . . . . . 24

8. Self-Absorption, Back Scattering, and Photon Contribution Correction Factor for Indium Folls Counted with an EndWindow Counter of $2.2 \mathrm{~cm}$. . . . . . . . . . . . .

9. Preferential Forward Scattering in Narrow Geometry as a Function of the Thickness of Indium Folls . . . . . . . . . 26 


\begin{abstract}
Correction factors for the effect of thickness on the self-scattering, selfabsorption and backscattering of beta particles from indium foils have been determined. Foils from 0.03 to $100 \mathrm{mg} / \mathrm{cm}^{2}$ were prepared on essentially weightless backings and activated by irradiation in a standard geometry in a solution nuclear reactor. The activated foils were counted in a $2 \pi$ windowless proportional flow counter and in a standard end window GM detector with and without a thick backing of silver.

The data were corrected for the fraction of activity which was produced by epithermal neutrons, the self-shielding of thermal neutrons by the foil during irradiation, the small contribution by the backscatter from the foil support, and the contributions of gamma and $X$-rays to the counting rate.

The multiple beta spectra of indium produced a minimum in the selfabsorption and self-scattering correction curve in the GM detector at about $1 \mathrm{mg} / \mathrm{cm}^{2}$ of sample and a maximum at about $12 \mathrm{mg} / \mathrm{cm}^{2}$ of sample. This is due to the balancing of the effects of self-absorption and preferential forward scattering in the narrow geometry GM detector. The self-absorption curve for indium in the $2 \pi$ counter has the expected shape for a beta emitter with multiple spectra.

The self-scattering and self-absorption correction factors for a 100 $\mathrm{mg} / \mathrm{cm}^{2}$ indium foil are approximately 1.5 for a GM detector at 7 per cent geometry and about 3 for a $2 \pi$ counter.

This report is based upon studies conducted for the Atomic Energy Commission under Contract AT-11-1-GEN-8.
\end{abstract}


-

6

1

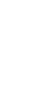

.

-




\section{INTRODUCTION}

The induced beta activity of indium folls is frequently used to evaluate thermal neutron fluxes or to calıbrate thermal neutron radiation meters. One method of obtaining absolute thermal neutron fluxes is to use a combination of an indium foll and counter which has been calibrated by a known neutron flux, such as that obtainable by using a standard pile. An alternative method would be to determine the absolute disintegration rate of an activated indium foil in conjunction with the known thermal neutron capture cross section. This laboratory is interested in the possibility of developing the latter method For this reason, study was made of some of the problems involved in making measurements of the absolute disintegration rates of indium foils.

It would be desirable to expose all the forls so that every mass element of each foll received the same kind and amount of exposure. Then the measured activations per unit mass would reflect only beta self-shielding and scattering effects, as far as the foll is concerned. However, there are two neutron effects which prevent this ideal type of exposure. The beam used contained both epithermal and thermal neutrons. Whereas there is but a small self-shielding effect for thermal neutrons (and this accounted for in this work), there is a very strong absorption by the foll at the indium resonance energy of $1.4 \mathrm{ev}$. For this reason, measurements were made of the cadmium ratio so that a computation would be possible of the fractions of the induced activity due to thermal neutrons alone. This will lead, of course, to estimation of the absolute disintegration rate of the foll due to activation by thermal neutrons alone.

Determination of absolute beta activities requires the knowledge of the effects introduced by the sample's self-absorption and self-scatter, absorption in the alr and window of the detector, the geometry and efficiency of the detector, backscattering of the sample support, and contributions from radiations other than betas resuling from the decay of the nucleus. Though many workers have given calculated and experimental correction factors for various effects, $1,2,3$ no data have been found in the literature that would be directly applicable to indium. In general, such data may not be applicable unless the true disintegration energy and decay scheme of the isotope is well known

For much of the existing data on the measurement of absolute beta activity from thick samples there is the difficulty that the usual detector employed, an 
end-window GM counter, discriminates against the low energy portion of the direct and scattered components of the beta ray spectrum. Nervik, ${ }^{4}$ Baker, and Collie, et al. ${ }^{6}$ have pointed out that the angular distribution of beta particles emitted by an isotope varies markedly with sample thickness. Thin samples emit betas isotropically. However, thicker samples cause the angular distribution of the electrons to approximate a cosine function: i. e. there is a preferential forward distribution. Thus, the use of a narrow geometry end-window detector to obtain self-absorption data will result in curves that contain the effect of different angular distributions for each thickness of sample used. In the case of a counter subtending a very small solid angle about the normal to a thick specimen, the observed activity per unit solid angle will be twice the average obtained by measuring over all angles. This phenomenon may prevent one from extrapolating self-absorption data to zero thickness of sample unless rather complete absorption data are obtained from nearly weightless specimens. If self-absorption curves are obtained with a $2 \pi$ geometry detector, the angular distribution variations for different sample thicknesses will not affect the counting rate.

Correction for the absorption by air and in the window of the detector is usually made by extrapolating an absorption curve. However, it is known that the shape of the absorption curve depends critically on the positions of the absorbers with respect to the source and window. ${ }^{2}$ Without a theory relating the absorption and scattering of air (and window) with that of the absorbers, there exists no guide to the manner in which the extrapolation is to be made. These' difficulties are accentuated when an important fraction of the beta spectrum consists of low energy components. The use of a windowless detector eliminates the need for making corrections of this nature.

Backscattering from the sample support can be minimized by making the support much thinner than the sample. By additional measurements with thick sample supports, backscattering factors can be determined.

Contributions from radiations other than betas can be evaluated by absorption measurements.

The purpose of this paper is to determine the correction factors for selfabsorption, self-scattering, and backscattering for a variety of indium foils. The 
absolute disintegration rate of an activated indium foil can then be determined from the observed activity of a foil whose thickness is within the range of the data presented.

\section{METHODS}

The absolute beta activity of a foil may be related to the counting rate per milligram (specific activity) as follows:

$$
A_{\text {th }}(x)=Q f_{b s} f_{s}^{f} \operatorname{eff}^{f} g e o m^{f}{ }^{f} \gamma
$$

where,

$A_{t h}(x)$ is a computed counting rate per milligram at the end of an ir radiation.

$Q$ is the absolute disintegration rate per milligram (arising from activation by the thermal neutrons alone).

$f_{b s}$ is the backscattering correction factor and is the ratio of counting rate with backscattering to counting rate with no backscatterer.

$f_{s}$ is the self-absorption and self-scattering correction factor and is the ratio of the counting rate of the sample to the counting rate of a sample with the same activity but of zero thickness.

$f_{e f f}$ is the efficiency factor of the detector system and is the ratio of the number of betas actually.counted to the number incident on the counting volume.

f geom is the geometry factor and is the ratio of the solid angle subtended by the detector window at the source to $4 \pi$.

$x$ is the thickness of indium foil in milligrams $/ \mathrm{cm}^{2}$.

$f_{w}$ is the factor to account for air and window absorption.

$f_{y}$ is the photon counting correction factor and is the ratio of the observed counting rate due to photons plus betas to the counting rate that would result for betas alone.

The quantity $A_{t h}(x)$ is a computed one and is obtained from the measured activity $A(x)$ by applying two corrections involving neutron effects. These are described in detail in Appendix $A$. The measured activity $A(x)$ is related to the computed one $A_{t h}(x)$ as follows:

$$
A_{t h}(x)=\frac{A(x) R(x)}{a(x)}
$$


where,

$A(x)$ is the total specific activity.

$R(x)$ is the fraction of the total activity due to thermal neutrons only, if there were no self-shielding of the foll to thermal neutrons.

$\alpha(x)$ is the ratio of the activity induced by thermal neutrons to that which would have been induced in the foll if there were no neutron flux depression caused by the foll acting as a thermal neutron sink. It is also the relative activation per unit mass induced in foils of various thicknesses, when all are exposed to the same integrated thermal neutron flux.

Since indium has a relatively short half-life of 543 minutes, the observed count must be corrected in various ways in order to obtain $A(x)$ Let $M$ be the observed number of counts per milligram in a time interial $t_{c}$, and $t_{w}$ the waiting time between the end of irradiation and the start of counting. One may compute $A(x)$ in terms of these observed and known parameters as follows

$$
A(x)=\frac{\lambda M e^{\lambda t} w}{\left(1-e^{-\lambda t} c\right)}
$$

where,

$\lambda=$ the decay constant of indium in $\mathrm{min}^{-1}$.

Equations (1) and (2) may be combined to obtain $f_{s}$, the self-absorption and self-scattering correction factor

$$
f_{s}=\frac{1}{Q f_{\text {geom }}} \cdot \frac{1}{f_{\text {eff }} \cdot f_{w}} \cdot \frac{\frac{A(x) R(x)}{a(x)}}{f_{\gamma} f_{b s}}
$$

\section{MATERIALS}

All the folls used were commercially pure indium (purity 99.97 per cent) with dimensions 1.0 centimeter by 1.0 centimeter, and with thicknesses ranging from $100 \mathrm{mg} / \mathrm{cm}^{2}$ down to approximately $30 \mu \mathrm{gm} / \mathrm{cm}^{2}$. In the range from 100 $\mathrm{mg} / \mathrm{cm}^{2}$ to $20 \mathrm{mg} / \mathrm{cm}^{2}$, rolled foll material was used. Indium folls of $15 \mathrm{mg} / \mathrm{cm}^{2}$ less were evaporated on supporting films using the apparatus pictured in Iig. 1. The folls in the thickness range $100 \mathrm{mg} / \mathrm{cm}^{2}$ to $1 \mathrm{mg} / \mathrm{cm}^{2}$ were supported by Formvar films mounted on thin aluminum rings. The Formvar films varied in thickness from 2.6 to $3.4 \mathrm{mg} / \mathrm{cm}^{2}$. For the very thinnest indium folls 
(1 $\mathrm{mg} / \mathrm{cm}^{2}$ to $30 \mu \mathrm{gm} / \mathrm{cm}^{2}$ ) the indium was evaporated on thin collodion films whose thickness was approximately $50 \mu \mathrm{gm} / \mathrm{cm}^{2}$. The methods used tor preparing the very thin collodion films are standard and have been described by

Warshaw ${ }^{7}$ and others. In one case the thin foll was prepared by evaporation onto $05 \mathrm{mg} / \mathrm{cm}^{2}$ Pliofilm.

All supporting films of the folls were mounted on 1.5-inch diameter graphite rings (see Fig. 2). Graphite was chosen as the supporting ring material both because of its low scattering cross section for the betas emitted by the activated indium and also because of its suitability for placement in the graphite moderator of the water boiler reactor used for the irradiation. Additionally, the graphite used is sufficiently pure so that no induced long-lived contaminant activities interfered with the counting of the betas emitted by the indium.

All the rolled folls were weighed to determine their thicknesses For the evaporated foils down to $1 \mathrm{mg} / \mathrm{cm}^{2}$ the thickness was determined by weighing the assembly both before and after the evaporation of the indium. For the very thinnest indium foils the thicknesses were determined both by difference weighing and by a spectro-chemical technique. In this latter method the indium was dissolved into a known volume of $\mathrm{HCl}$. A portion of the sample solution was placed in a flame photometer and the intensity of an emission line of indium was compared with the intensity of the same line emitted by calibrated solutions of indium in $\mathrm{HCl}$. This method permits the determination of thicknesses tc within 2 per cent. The details of this method are being published elsewhere by a member of this laboratory. 8

\section{INSTRUMENTATION}

As mentioned above, considerable simplification is introduced if $f_{\text {eff }}$ and $\mathrm{f}_{\mathrm{w}}$ are equal to unity (see $\mathrm{Eq}$. (4)). If the detector has a $2 \pi$ counting geometry, the different angular distributions of the emitted betas for different sample thicknesses do not introduce an additional correction factor. Also a $2 \pi$ counting geometry has a higher counting yield as compared with background. For the above reasons, a windouless proportional counter with a $2 \pi$ geometry, for which $f_{\text {eff }}=f_{w}=1$, was used as the detector in these experiments.

Specifically, the detector used is a modified Nuclear Measurement Corporation proportional counter converter Model PCC-10. It is a flow counter using an argon-methane mixture at atmospheric pressure as the counting gas. 
The modification introduced permitted counting determinations to be made with and without a backscattering material. This was accomplished by replacing the standard brass support for samples by a hollow aluminum cylinder to support the indium foil assembly (see Fig. 3 and 4). The aluminum cylinder was made with a sufficient distance between the indium foil and the surrounding structure to eliminate all backscattering except that from the film supporting the indium.

Since most measurements of beta activities made in the past have been accomplished with GM detectors, it was decided to make a series of measurements for comparison of the results obtained with two different types of detectors. A standard GM counter, Tracerlab Model TGC-2 with a $1.9 \mathrm{mg} / \mathrm{cm}^{2} \mathrm{mica}$ end window, was used with the sample placed on the second shelf, 2.2 centimeters from the window. In order to perform the backless counting with the GM detector, a special aluminum support was used to hold the irradiated sample.

\section{EXPERIMENTAL}

\section{A. IRRADIATION PROCEDURE}

The indium was activated by placing it in a standard geometry in one of the graphite stringers in the reflector of the North American Aviation Inc., solution nuclear reactor (water boller). The irradiations for folls with thicknesses greater than $1 \mathrm{mg} / \mathrm{cm}^{2}$ were for a period of approximately 6 minutes at a power level of 0.1 watt. For the thinnest folls, power levels up to 1 watt and times of 12 minutes were employed. To normalize the exposure for the various power levels used, a monitor foll of $100 \mathrm{mg} / \mathrm{cm}^{2}$ was irradiated in a standard geometry in the reactor at the same time as the sample foll of interest. After withdrawal from the reactor, there was a waiting time of 20 minutes for those cases in which the mounts contained the aluminum supporting ring. Otherwise, virtually no waiting time was necessary. The waiting time allowed for the decay of the high level, short-lived activity of the aluminum ring supporting the Formvar.

\section{B. COUNTING PROCEDURE}

The activated indium foils were counted alternately in the $2 \pi$ proportional counter and in the GM detector with and without a thick backing of silver. Initial$y$, difficulties were met in the proportional counter in the form of decreasing counts beyond that expected from decay. This was due to charges accumulated 
on the semi-conducting films used as backing material for the indium. These effects were eliminated by using a polonium static eliminator in conjunction with brushing the film lightly before each count determination was made.

Total counts tabulated from the different foils, in the proportional counter ranged from approximately 6000 to 700,000 for foils of $30 \mu \mathrm{g} / \mathrm{cm}^{2}$ to $100 \mathrm{mg} / \mathrm{cm}^{2}$. For the low counting foils several repetitions of irradiations and counting for the same foil were made in order to decrease the statistical uncertainty. The corresponding total count in the GM detector ranged from 1000 to 100,000 counts for the same range of thicknesses. Three such counts were always taken and individually corrected for the wait time and counting time back to the moment of reactor shutdown. The average value of the three determinations was the finally accepted one. The total count for the $100 \mathrm{mg} / \mathrm{cm}^{2}$ monitoring foils was always in the range of 600,000 for the $2 \pi$ geometry and about 100,000 for the GM detector. The total count observed in the GM detector was corrected for dead time losses. In the $2 \pi$ detector no resolution corrections were necessary.

\section{BACKSCATTER OF THE SUPPORT}

The indium samples were supported by collodion, Pliofilm and Formvar used respectively for the lightest, intermediate, and heaviest indium samples. Each material had a backscattering effect which was a function of thickness of indium sample and the type of detector used. It was assumed that for small increments of thickness of the mounting material the backscatter was proportional to the thickness. In accordance with this, the backscatter was determined in the following way: an initial count was taken of the sample mounted on a given material; then an additional layer of mounting material was placed underneath the sample and a second count was taken. The ratio of this latter count to the former gives the backscatter factor for the increment of added mounting material employed, and for the thickness of indium sample used.

\section{RESULTS}

When thermal neutrons are used to activate foils, there is a self-shielding effect that results in a lowered activity per milligram for a thicker foil than for a relatively thin foil when both have been irradiated in the same isotropic integrated thermal neutron flux. Corrections for this effect have been computed on the basis of a method suggested by Bothe ${ }^{9}$ and are given in Appendix $B$. The data presented in this report have been corrected for this effect. 
The experimental data obtained from the neutron activation of indium foils are given in Tables B-I to B-IV. These tables also include information about the small corrections due to the thin mounting material used to support the backless samples.

The curves of Fig. 5 and 6 are based on data obtained with the $2 \pi$ proportional counter. Figure 5 gives $f_{s}$, the self-absorption correction factor for the case in which no backscattering material additional to the supporting film was used, whereas Fig. 6 gives $f_{s} f_{b s}{ }^{f} \gamma$ for a thick silver backing. The data in Fig. 7 and 8 were obtained in the end window GM counter with the sample always placed on shelf 2 (2.2 centimeters from the window). Figures 7 and 8 are respectively for the cases of no backscattering material and for silver backing.

A relatively small fraction of all counts in both types of detectors were due to gamma and $X$-rays emitted by the activated indium atoms. The correction factor, $f y$, for this effect was obtained by means of absorption curves, and the results are given in Tables B-I and B-III. For the GM detector the counts due to the photons were about 3 per cent of the total count. For the proportional counter the range was from 2 to 6 per cent going from the thinnest to the thickest foils. Figures 5 and 7 have been corrected for the contributions by photons. Thus, these data reflect counts due to betas only. Figures 6 and 8 , obtained with thick silver backing, have not been corrected for photon counts. This was done to simplify the procedure for making corrections to total counts so that the absolute counting rates of indium foils could be obtained by dividing observed counting rates by the ordinates of these curves.

\section{DISCUSSION OF RESULTS}

Figure 5 gives the self-absorption factor for indium with no backing, in a windowless $2 \pi$ geometry detector. The curves have the expected shape for a beta emitter possessing two or more continuous beta spectra. The effect of changing preferential forward scattering with increasing sample thickness has no effect on the count. Thus one observes only the effect of self-absorption which increases with the sample thickness. As is the case for an ordinary absorption analysis of a mixture of beta spectra, the initial steep portion of the semi-log plot arises mainly from the absorption of the lower energy component. The remaining portion of the semi-log plot arises from the absorption 
of the higher energy components. In the case of indium-116, there are three known beta spectra with estimated maximum energies of $0.6,0.87$, and $1.0 \mathrm{Mev}$ with relative intensities of 21,28 , and 51 per cent, respectively. 10 The authors of reference 10 state that 6 per cent of the total beta radiation deviates above the straight Fermi line at energies less than $250 \mathrm{Kev}$ indicating the presence of a lower energy component.

By contrast, Fig. 7 gives the self-absorption and self-scattering factor for indium, with no backing, obtained by using a thin window GM detector. Figure 7 exhibits the same characteristics as does Fig. 5 but with one added feature. In a narrow geometry detector, such as is the case here, there is the additional well-known effect of increasing preferential scattering in the forward direction with increasing sample thickness. The addition of this effect to that of the absorption of the multiple beta spectra produces the minimum (at about $1 \mathrm{mg} / \mathrm{cm}^{2}$ of sample) and the maximum (at about $12 \mathrm{mg} / \mathrm{cm}^{2}$ of sample) shown in Fig. 7. The first portion (less than $1 \mathrm{mg} / \mathrm{cm}^{2}$ ) of $F i g .7$ is due to selfabsorption of the soft beta spectrum. As. the sample thickness increases the preferential forward scattering tends to increase the count. The balancing of these two effects produces the minimum. Further increases in sample thickness cause an actual increase in counts due to the increased effect of the preferential forward scattering. However, the absorption of the more energetic components of the beta spectra present becomes important also. The balancing of these latter two effects produces the maximum that is observed.

The maximum in Fig. 7 is equal to 1.24 and occurs for thicknesses in the range of 12 to $18 \mathrm{mg} / \mathrm{cm}^{2}$. This value and range of the maximum is in good agreement with results reported by Nervik and Stevenson ${ }^{4}$ for $\operatorname{Pr}^{143}$. whose beta $E_{\max }=0.92 \mathrm{Mev}$, corresponding to the average of the betas from indium116.

It has been shown ${ }^{5}$ that the increased forward scattering with a thick sample into a narrow geometry detector results in recording an activity per unit solid angle which is twice that which would be observed if the detector counted an average over all angles. To check this point the curve shown in Fig. 9 was computed. The ordinate is the ratio of the sample activity as measured with the narrow geometry detector to that determined with the $2 \pi$ detector (which effectively measures an average over all angles); $i . e .$, the 
tio of Fig. 7 or Fig. 8 to Fig. 5 or Fig. 6 respectively. As Fig. 9 indicates, the ratio of small geometry activity $k<2 \pi$ ) to that of the $2 \pi$ geometry activity varies from unity at small thicknesses (no preferential scattering) to approximately 2.1 at the greater foil thicknesses. The 5 per cent deviation from 2.0 is within the limits of the estimated experimental error.

Further evidence to support the above explanation is the fact that the initial slope of both Fig. 5 and 7 are very nearly the same; e.g., at 350 $\mu \mathrm{gm} / \mathrm{cm}^{2}$ of sample, both curves are down to about 90 per cent of the initial value (see magnified portions of these figures). The same self-absorption is occurring in both samples in the two detectors; however, the additional phenomena of preferential forward scattering in a narrow geometry detector is not important for sample thicknesses of indium less than $1 / 2 \mathrm{mg} / \mathrm{cm}^{2}$. Thus, one would expect the same absorption curves for both detectors for these extremely thin samples.

One may obtain quite complex self-absorption curves when a narrow geometry GM detector is used. In the present case, the use of a relatively thin window (1.9 $\left.\mathrm{mg} / \mathrm{cm}^{2}\right)$ and an air absorption path of $2.5 \mathrm{mg} / \mathrm{cm}^{2}$ permitted this initial soft component absorption to be observed. Had the GM window been 3 to $5 \mathrm{mg} / \mathrm{cm}^{2}$ in thickness, the energy cutoff would have been such that the initial portion of Fig. 7 would not have been detected. Instead one would.have observed a curve similar to those reported in the literature with a simple maximum. For a beta emitter with a single beta spectrum, of relatively high energy, this effect of the air-window thickness is not critical. On the other hand if the spectra are multiple in nature and contain appreciable percentages of low energy components, very thin air-window thicknesses are necessary to enable useful self-absorption curves to be obtainable. Because of these complexities it is better to employ $2 \pi$ or $4 \pi$ detectors with thin or no windows to obtain accurate self-absorption data.

Figures 6 and 8 were obtained with thick silver backing. The backscattering factor for an infinitely thin sample is approximately 1.67 for the narrow geometry detector. This value of the backscattering factor for silver is consistent with values quoted in the literature for comparable circumstances. The backscattering factor for the $2 \pi$ counter with similar sample conditions is

63. These values for the backscatter factors for silver have been corrected for the effect of photon counts. 
As the sample thickness increases one would expect the backscattering - factor to approach unity for all detectors. The ratio of Fig. 5 and 6 and Fig. 7 and 8 show backscattering factors of about 1.04 for both detectors at a sample thickness of $100 \mathrm{mg} / \mathrm{cm}^{2}$ when both have been corrected for the effect of photons.

The correction to be applied to a $100 \mathrm{mg} / \mathrm{cm}^{2}$ foil to compensate for the effect of self-absorption is almost 3 in $2 \pi$ geometry. The self-scattering and self-absorption correction for a $100 \mathrm{mg} / \mathrm{cm}^{2}$ foil counted in a GM detector with 7 per cent geometry is approximately 1.4. In practical applications when an infinite silver backing is used for supporting the foils the corresponding correction factors are 2.7 and 1.33 .

\section{ERRORS}

The estimated errors that affect the accuracy of the curves in Fig. 5 and 6 include the following:

a. Foil weights; estimated error $\leq 2$ per cent.

b. Counting error; estimated $\leq 3$ per cent.

c. Errors in estimating counts due to backscattering of supporting film, gamma rays, neutron self-shielding $<3$ per cent.

d. Errors in cadmium ratio; estimated $\leq 1.5$ per cent.

The estimate of total error based on the above is approximately 5 per cent. (Computed as the square root of the sum of squares of the individual errors.) 


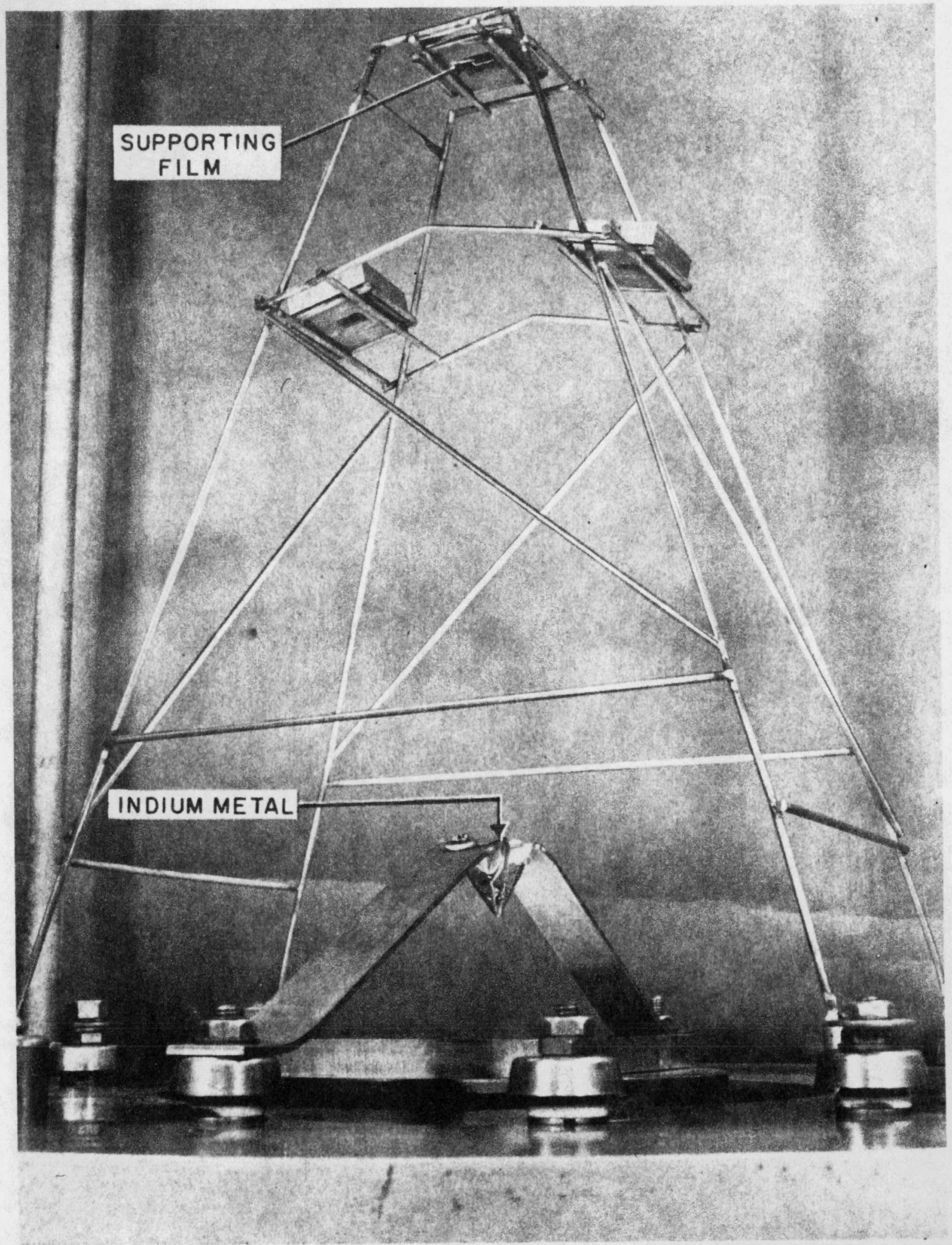

SRP $15-4 A$

Fig. 1. Evaporation Apparatus for Making $1 \mathrm{~cm}^{2}$ Indium Foils 


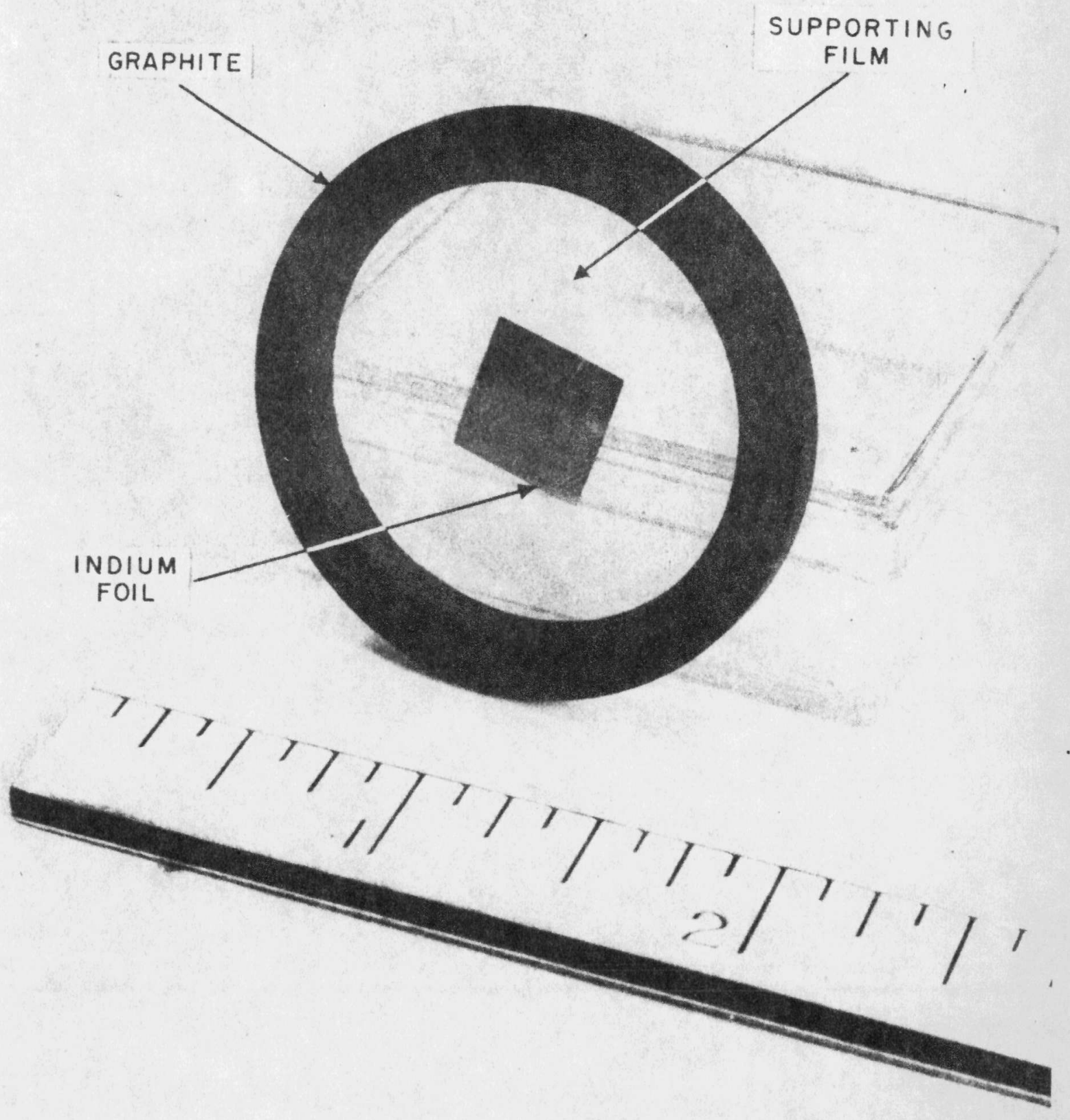

Fig. 2. A $1 \mathrm{~cm}^{2}$ Indium Foil Evaporated on a Collodion $\mathrm{SRP} 15-3 \mathrm{~B}$ Supporting Film and Mounting by Concentric Graphite Rings 


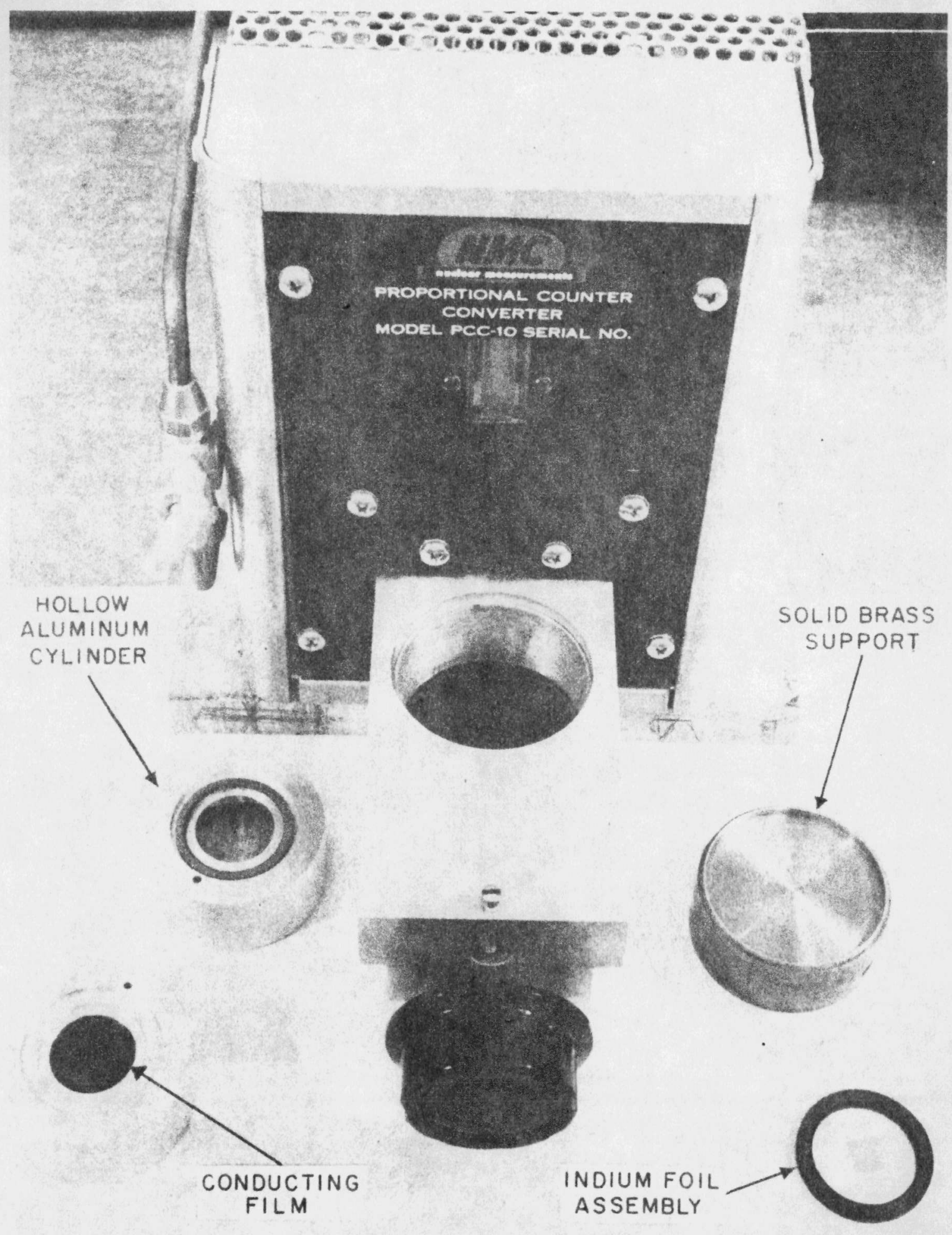

SRP $15-3 A$

Fig. 3. Modified Nuclear Measurement Corporation $2 \pi$ Proportional Counter 


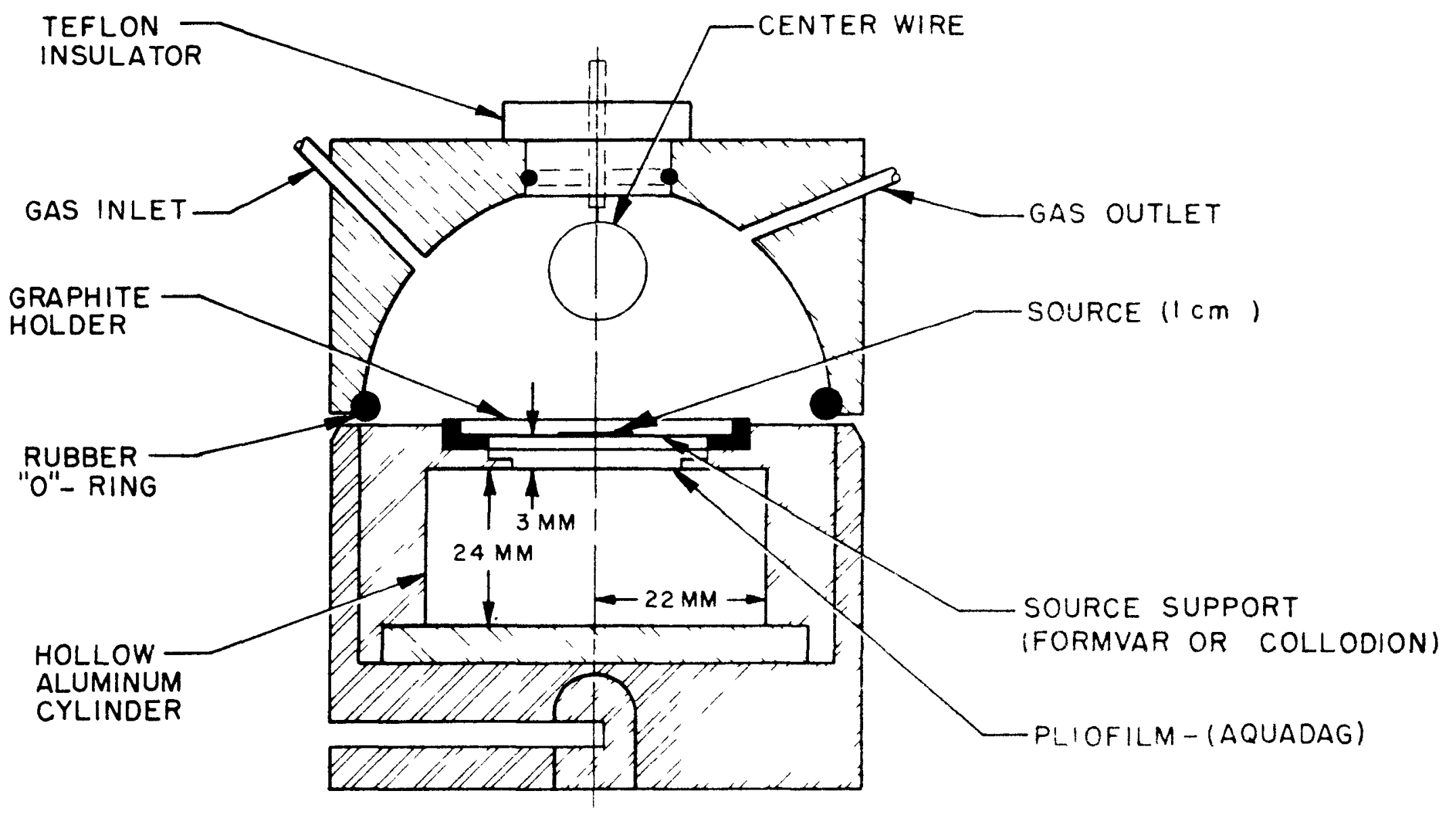

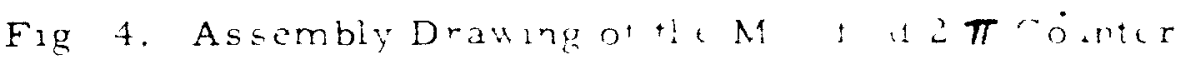




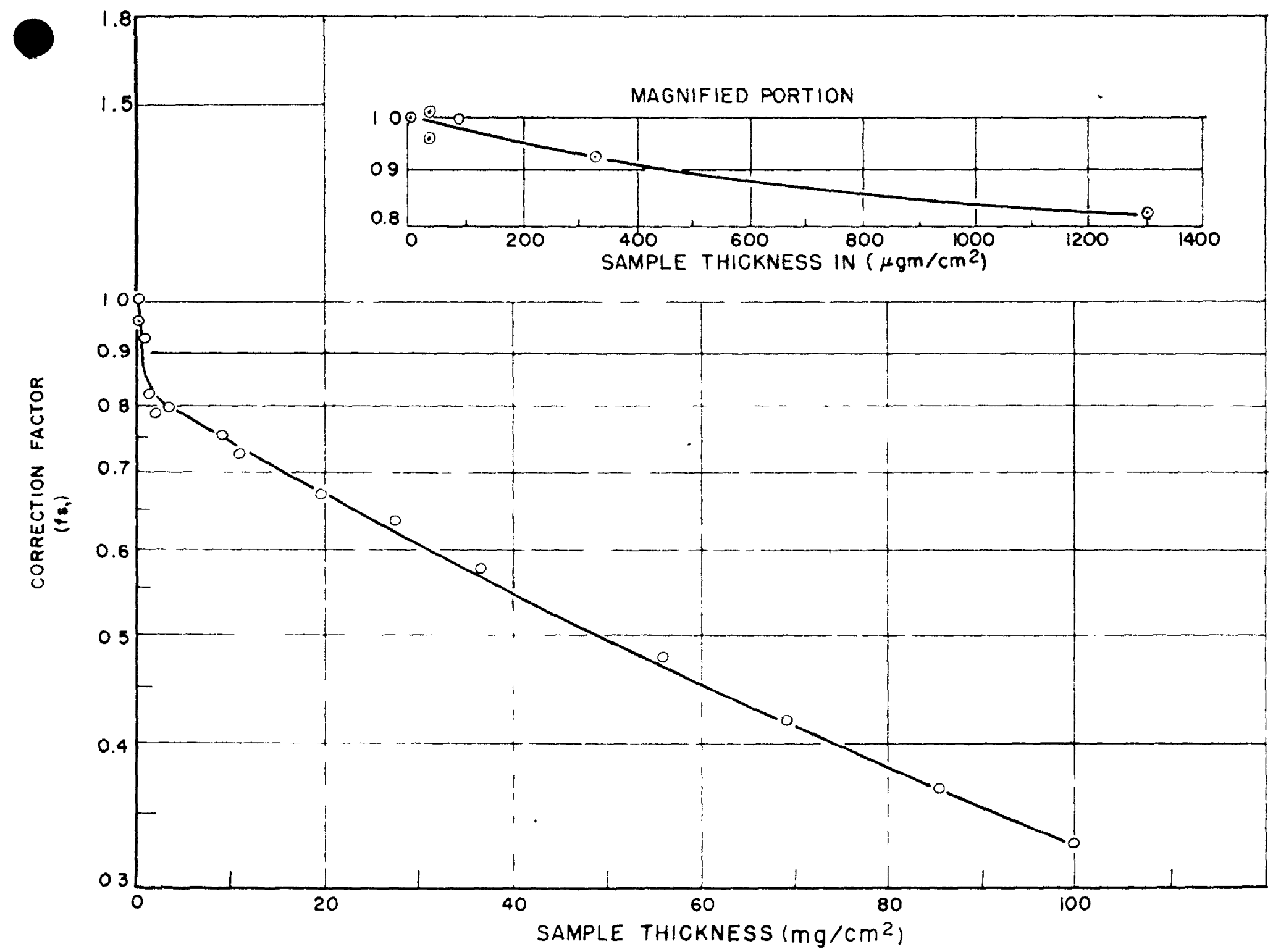

$\sigma$

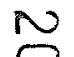

Fig. 5. Self-Aburption Correction Factur tor Banless Indium Foils

in a $2 \pi$ Windowlea- Counter 


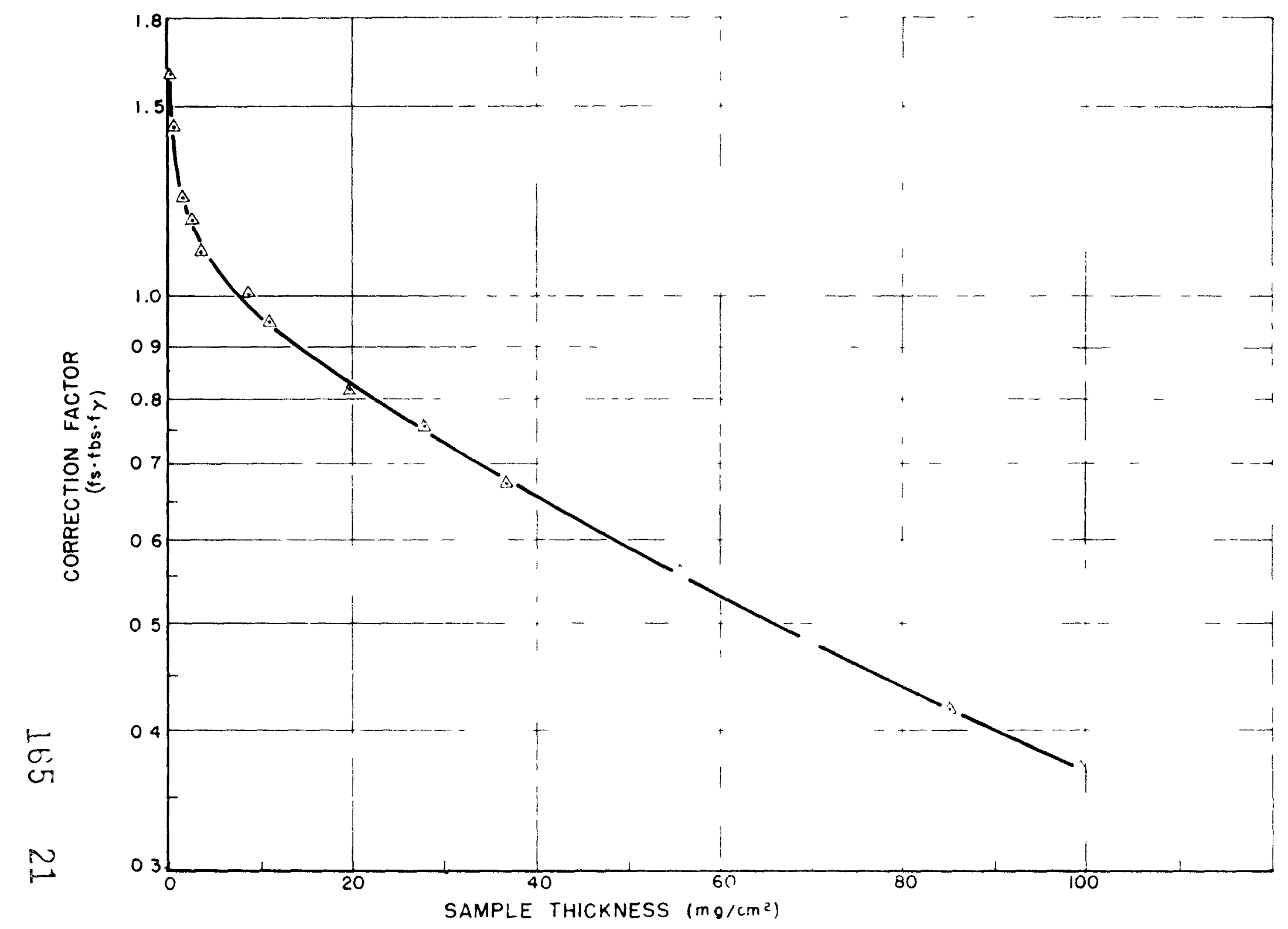

Fig. 6. Self-Absorption, Back Scattering, and Photcin Contribution Correction Factor for Indium Folls Counted on Thack Silver Barking a $2 \pi$ Windowless Counter 


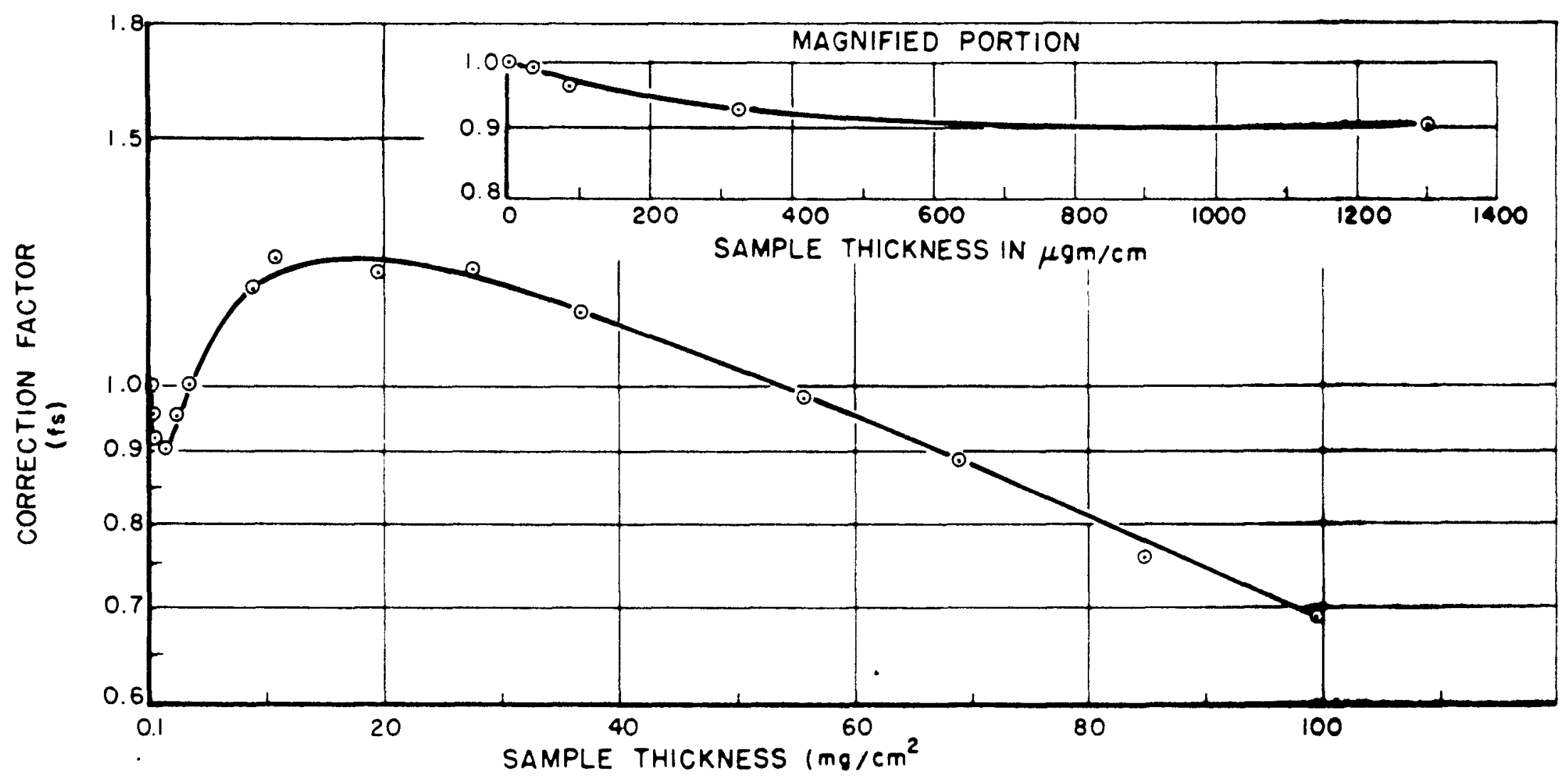

v

Fig. 7. Self-Absorption Correction Factor for Indium Foils Counted with an End Window GM Counter at $2.2 \mathrm{~cm}$ 


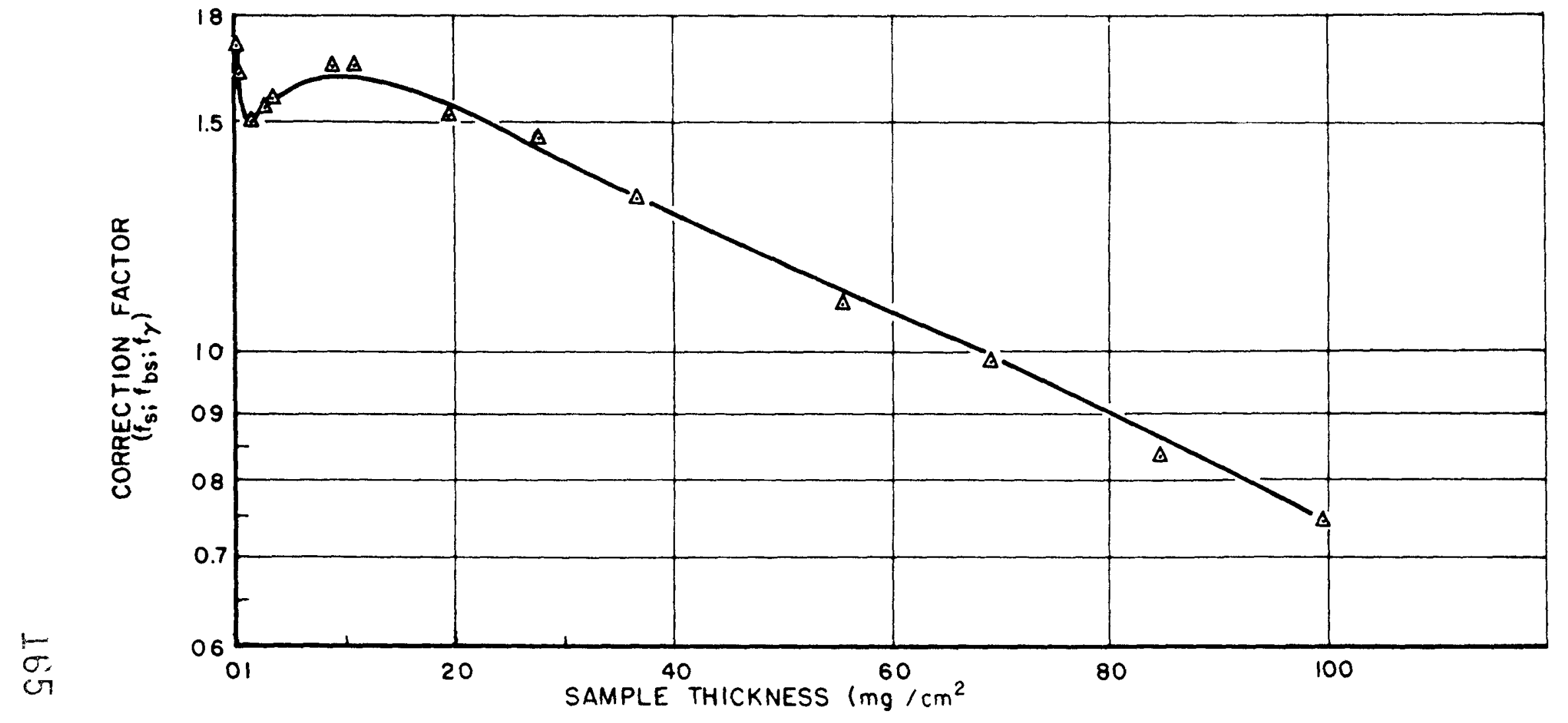

$\underset{\omega}{\omega}$

Fig. 8 Self-Absorption, Back Scattering, and Photon Contribution Correction Factor for Indium Folls Counted with an End-Window GM Counter of $2.2 \mathrm{~cm}$ 


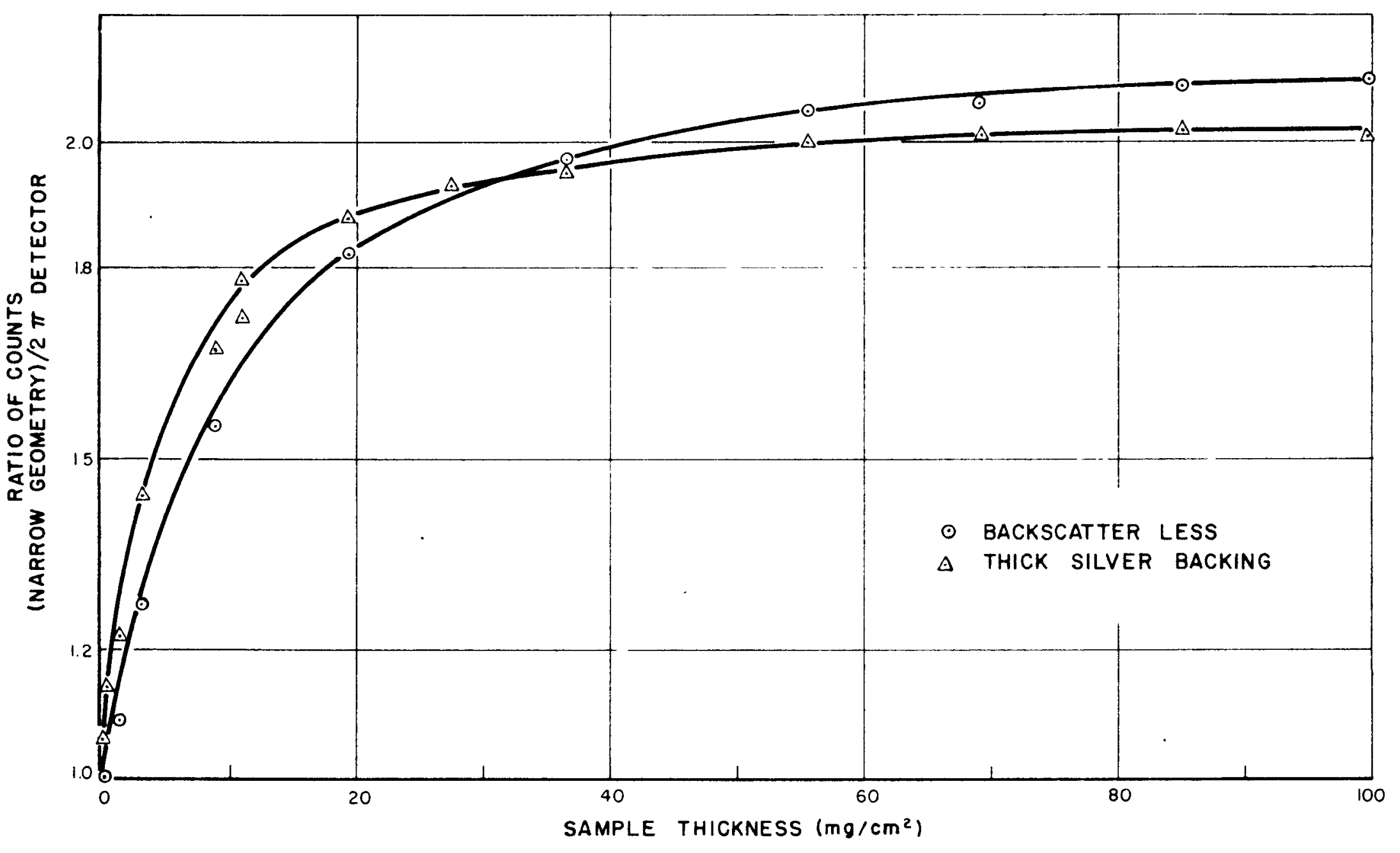

Fig. 9. Preferential Forward Scattering in Narrow Geometry as a Function of the Thickness of Indium Foils 


\section{APPENDIX A}

\section{CORRECTION OF SPECIFIC ACTIVITY DUE TO NEUTRON EFFECTS}

Equation ( 1$)$ defines $A_{t h}(x)$ as the computed activity due to thermal neutrons, and includes a correction for the self-shielding of the foil.

Let the relation between $A_{t h}(x)$ and the measured bare activity of the foil, $A(x)$, be restated as follows:

$$
A_{t h}(x)=\frac{A(x) R(x)}{a(x)}
$$

where,

$R(x)$ is the fraction of the total activity due to thermal neutrons, if there were no self-shielding of the foil to thermal neutrons.

$a(x)$ is the ratio of the activity induced by thermal neutrons to that which would have been induced in the foil if there were no neutron flux depression i.e., the relative activation per unit mass.

\section{Cadmium Ratio}

Computation of $R(x)$ has been based on data obtained by exposing a variety of indium foil thicknesses which were irradiated alternately with cadmium covers and bare. This procedure allowed the determination of the cadmium ratio (CR); i. e., the ratio of the bare to the cadmium covered activities. Cadmium ratios for relatively thick foils give the ratio of epithermal to thermal activities, but not the ratio of epithermal to thermal fluxes. This is due to the fact that thick indium foils are effectively, "black" to $1.44 \mathrm{ev}$ resonance neutrons while the absorption of thermal neutrons by the same foil is considerably less. Thus, the $C R$ varies as a function of indium foil thickness. In order to compute flux ratios or thermal flux only, it is necessary to use extremely thin foils in which the effects described above are negligible.

The various measured and computed activities presented in this report are related as follows:

Let $A(x)$ be the total activity; let $A_{\text {th }}(x)$ and $A_{\text {epi }}(x)$ be respectively the activities induced by the thermal and epithermal fuxes in an indium foil whose thickness is $x \mathrm{mg} / \mathrm{cm}^{2}$, assuming that there is no.self-shielding of the foil for thermal neutrons. 
$A(O), A_{t h}(O), A_{\text {epi }}(O)$ are similarly the activities induced in a very thin foil (in our case by extrapolating $A(x), A_{t h}(x), A_{\text {epi }}(x)$ to $x=0 \mathrm{mg} / \mathrm{cm}^{2}$.

The total induced activity in a bare foil of thickness $x \mathrm{mg} / \mathrm{cm}^{2}$ is given by:

$$
A(x)=A_{t h}(x)+A_{\text {epi }}(x) \text {. }
$$

The relation between $A_{e p i}(x)$ and the cadmium covered activity, $A_{C d}(x)$ is,

$$
A_{\text {epi }}(x)=F A_{C d}(x)
$$

where,

$F=1.05$ for the 0.020 -inch cadmium used in this experiment and takes account of the epithermal neutron absorption by the cadmium.

The cadmium ratio is defined as:

$$
C R(x)=\frac{A(x)}{A_{C d}(x)}
$$

thus,

$$
A_{t h}(x)=A(x)\left[1-\frac{F}{C R(x)}\right]
$$

therefore,

$$
R(x)=\left[1-\frac{F}{C R(x)}\right] .
$$

This is the relation used to compute the fraction of the induced activity in a bare foil due to thermal neutrons in terms of the cadmium ratio for a given foil of thickness $(x) \mathrm{mg} / \mathrm{cm}^{2}$ and is given in Table $B-1$.

\section{Effect of Thermal Neutron Flux Depression}

The analysis presented in this paper assumed that the induced activity per milligram was the same for foils of all thicknesses. The use of a monitor - foil did insure that all the observed activities were referenced to the same integrated thermal neutron flux. However, the fact that the foils do absorb thermal neutrons results in a diminution of flux as a function of foil thickness. Thus, there will be a lower activity per milligram for a thicker foil than for a relatively thin one when both have been irradiated in the same isotropic integrated thermal neutron flux. 
A treatment of this self-shielding phenomenon is given by Bothe ${ }^{10}$ in terms of the parameter $\left(\Sigma_{a} \cdot d\right)$ where $\sum_{a}$ is the macroscopic absorption coefficient for thermal neutrons in indium and $d$ is the thickness of the foil. For the reaction $\operatorname{In}^{115}(\mathrm{n}, \gamma) 54^{\mathrm{m}} \mathrm{In}^{116}$ the microscopic absorption coefficient is given by $\sigma_{\mathrm{a}}=197$ barns. 11 The density $\rho$ is $7.28 \mathrm{gm} / \mathrm{cm}^{3}$. The atomic weight of indium is $114.8 \mathrm{gm} / \mathrm{mol}$. From this data one computes: $\sum_{\mathrm{a}}=7.20 \mathrm{~cm}^{-1}$. Bothe gives the following relative activation per unit mass, $a(x)$, as a function of $\left(\Sigma_{\mathrm{a}} \cdot \mathrm{d}\right)$.

TABLE A-1

RELATIVE ACTIVATION PER UNIT MASS OF INDIUM FOILS

\begin{tabular}{l|c|c}
\hline$\sum_{\mathrm{a}} \cdot \mathrm{d}$ & $\mathrm{X}(=\rho \mathrm{d}) \mathrm{mg} / \mathrm{cm}^{2}$ & $\begin{array}{c}\text { Relative Activation } \\
\text { Per } \alpha(\mathbf{x}) \text { Unit Mass }\end{array}$ \\
\hline 0 & 0 & 1.000 \\
0.02 & 20.4 & 0.950 \\
0.05 & 50.5 & 0.902 \\
0.10 & 101. & 0.838 \\
0.20 & 202. & 0.747 \\
\hline
\end{tabular}

The relative activation per unit mass, $a(x)$, was computed for every foil thickness used and is presented in the tables of Appendix B. The data in Appendix $B$ is corrected for this self-shielding effect in accordance with Eq. (2). A comparison of this theoretical correction was made with some experimental work done by the California Research and Development Co. ${ }^{12}$ They measured the relative saturated activity per unit volume of indium foils as a function of foil thickness. They obtained values which agree well with Bothe's theory for their experimental arrangement. 


\section{APPENDIX B}

\section{ABSOLUTE SPECIFIC ACTIVITY OF INDUM FOILS}

The experimental data obtained from the neutron activation of indium foils are given in Tables B-I to B-IV. The total specific activity of each foil used is listed in the second column. These values have been corrected for the waiting time after irradiation to the start of counting, and the counting time (see Eq. 3). The corrected thermal specific activity for zero weight foils was obtained by extrapolation using data from the first few thinnest foils. The relation, $A(x)$, between the factors tabulated is defined by Eq. (4). 
DATA TABLE B-I

$2 \pi$ DETECTOR WITH NO BACKSCATTERER

$$
f_{\text {eff }}=1 ; f_{w}=1
$$

\begin{tabular}{|c|c|c|c|c|c|c|c|c|c|}
\hline $\begin{array}{l}\text { Indium } \\
\text { Weight } \\
\times \mathrm{mig} / \mathrm{cm}^{2}\end{array}$ & $\begin{array}{c}\text { Total } \\
\text { Specilic } \\
\text { ALtivity } \\
A(x)\end{array}$ & $\begin{array}{l}\text { Cadmium } \\
\text { Ratio } \\
\text { CR(x) }\end{array}$ & $\begin{array}{c}\text { Fraction of } \\
\text { Total } \\
\text { Sideratic Autisiy } \\
\text { Due Io } \\
\text { Thermal Neutrons } \\
R(x)\end{array}$ & $\begin{array}{c}\text { Thermal Neutron } \\
\text { Selt-Shieldang } \\
\text { Correctin Factor } \\
\text { Relative Activation } \\
\text { Per thut Mass } \\
\qquad a(x)\end{array}$ & $\begin{array}{l}\text { Compited } \\
\text { Thirmal } \\
\text { Sperifie Activity } \\
A_{i h}(x)\end{array}$ & $\begin{array}{c}\text { Photon } \\
\text { Correction } \\
\text { Factor } \\
t_{\gamma} \\
\end{array}$ & $\begin{array}{c}\text { Backsidtering } \\
\text { Corrtior } \\
\text { Factor } \\
\text { Due to Support } \\
\text { tbs }\end{array}$ & 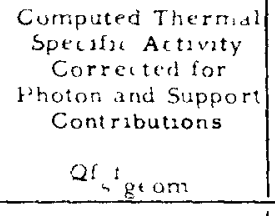 & $\begin{array}{c}\text { Selt-Absorption } \\
\text { and } \\
\text { Self-Scattering } \\
\text { Correction } \\
\text { Factor } \\
\text { s }\end{array}$ \\
\hline 0 & & 2.385 & 0.7603 & 1.00 & & & & $6523 \%$ & 1 \\
\hline 0.0340 & 12149 & 2.385 & 0.5609 & 1.00 & 6814 & 1.019 & 1.008 & 6630 & 1.016 \\
\hline 0.0307 & 11435 & 2.385 & $0.5600^{3}$ & 100 & +414 & 1.019 & 1.608 & $0: 41$ & 0.957 \\
\hline 0.0828 & 11801 & 2.405 & $0.564 t$ & 1.00 & 0664 & 1.020 & 1.008 & 0477 & 0.993 \\
\hline 0.325 & 10926 & 2445 & 0.5718 & 1.00 & 1240 & 1.021 & 1.019 & $0 n 00$ & 0.920 \\
\hline 1.30 & 9582 & 2.57 & 0.5920 & $0.49 \mathrm{e}$ & 3701 & 1.023 & 1.040 & 5356 & 0.821 \\
\hline 2.1 & 8833 & 2.72 & 0.0103 & 0.093 & 5580 & 1.024 & $103 t$ & 5257 & $0.80 t$ \\
\hline 3.074 & 8644 & 2.80 & 0.6263 & 0.990 & 5,408 & 1.020 & $1.03 \pi$ & 5173 & 0.793 \\
\hline 8.86 & 7114 & $3.4 i$ & 0.6444 & 0.975 & 5067 & $1.0,30$ & 1.001 & 4915 & 0.753 \\
\hline 10.819 & 6621 & 3.60 & 0.7098 & $0.9+80$ & $4 \times 52$ & 1.031 & 1.000 & 4705 & 0.721 \\
\hline 19.384 & 5631 & 4.30 & 0.7574 & 0.951 & 4484 & 1.035 & 1.000 & 4333. & 0.664 \\
\hline 27.408 & $507 t$ & 4.89 & 0.7869 & 0.930 & $42 t, i$ & $1, n 34$ & 1060 & 4100 & 0.630 \\
\hline 30.558 & 4451 & 5.40 & 0.8073 & 0.923 & 3897 & 1042 & $i 000$ & 3736 & 0.573 \\
\hline 55.492 & 3528 & 5.98 & 0.8261 & 0.845 & 3256 & 1043 & 1.000 & 3121 & 0.478 \\
\hline 69.014 & 3051 & 6.16 & 0.8312 & 0.877 & 2890 & 1.044 & 1.000 & 2743 & 0.420 \\
\hline 85.06 & 2594 & 0.25 & 0.8337 & 0.858 & 2520 & 1.058 & 1.000 & 2381 & 0.365 \\
\hline 99.58 & 2304 & 6.27 & 0.8342 & 0.840 & 2287 & 1001 & 1.000 & 2154 & 0.330 \\
\hline
\end{tabular}

* Obtained by extrapolation of $Q f_{s} f_{\text {geom }}$ to its value of $Q f$ geom $a t x-0$ mp, $\mathrm{Lm}^{2}$ 
DATA TABLE B-II

$2 \pi$ DETECTOR WITH THICK SILVER BACKING

$$
f_{\text {eff }}=1 ; f_{w}=1
$$

\begin{tabular}{|c|c|c|c|}
\hline $\begin{array}{l}\text { W eight } \\
\text { (mg) } \\
\quad \mathbf{x}\end{array}$ & $\begin{array}{l}\text { Total } \\
\text { Specific } \\
\text { Activity } \\
\quad A(x)\end{array}$ & $\begin{array}{l}\text { Computed Thermal } \\
\text { Specific Activity } \\
\mathrm{A}_{\mathrm{th}}(\mathrm{x})=\mathrm{Qf} \mathrm{geom}\left(\mathrm{f}_{\mathrm{g}} \mathrm{f}_{\mathrm{bs}} \mathrm{f} \gamma^{*}\right.\end{array}$ & $\begin{array}{l}\text { Correction Factor for } \\
\text { Self-Absorption and } \\
\text { Self-Scattering, Infinite } \\
\text { Silver Backscatterer and } \\
\text { Photons } \\
\qquad\left(f_{8} \cdot f_{b s} \cdot f_{\gamma}\right)^{* *}\end{array}$ \\
\hline 0.0 & & 10830 & 1.66 \\
\hline 0.0346 & 18629 & 10450 & 1.60 \\
\hline 0.0367 & 18568 & 10415 & 1.60 \\
\hline 0.0827 & 18851 & 10643 & 1.63 \\
\hline 0.325 & 16435 & 9398 & 1.44 \\
\hline 1.3 & 13348 & 7942 & 1.22 \\
\hline 2.1 & 12191 & 7554 & 1.16 \\
\hline 3.074 & 11114 & 7031 & 1.08 \\
\hline 8.86 & 9072 & 6462 & 1.00 \\
\hline 10.819 & 8326 & 6102 & 0.94 \\
\hline 19.384 & 6596 & 5253 & 0.81 \\
\hline 27.408 & 5817 & 4890 & 0.75 \\
\hline 36.558 & 4974 & 4356 & 0.67 \\
\hline 55.492 & 3894 & 3594 & 0.55 \\
\hline 69.014 & 3311 & 3138 & 0.48 \\
\hline 85.06 & 2800 & 2720 & 0.417 \\
\hline 99.58 & 2442 & 2425 & 0.371 \\
\hline
\end{tabular}

* Corrected by use of Eq. 2 with same values for $R(x)$ and $a(x)$ as in Table $B-I$. ** Obtained by dividing column 3 by Qf geom from Table B-I. 
DATA TABLE B-III

\section{GM DETECTOR WITH NO BACKSCATTERER}

$f_{\text {eff }}=1$

\begin{tabular}{|c|c|c|c|c|c|c|c|c|c|}
\hline $\begin{array}{r}\text { Indrum } \\
\text { Werght } \\
\times \mathrm{mg}^{\prime} \mathrm{cm}^{2}\end{array}$ & $\begin{array}{l}\text { Iotal } \\
\text { Specitic } \\
\text { Activity } \\
\mathbf{A}(\mathbf{x})\end{array}$ & $\begin{array}{l}\text { Cadmium } \\
\text { Ratio } \\
\text { CR(x) }\end{array}$ & $\begin{array}{c}\text { Fration of } \\
\text { Total } \\
\text { Specific Activity } \\
\text { Due To } \\
\text { Ihermal Neutrons } \\
\mathrm{R}(\mathrm{x})\end{array}$ & $\begin{array}{l}\text { Thermal Noutron } \\
\text { Stif-Shielding } \\
\text { Correction Factor } \\
\text { Relatib Ailliation } \\
\text { Per Unit Mass } \\
\qquad g(x)\end{array}$ & $\begin{array}{l}\text { Computed } \\
\text { Thermal } \\
\text { Specific Activity } \\
\mathbf{A}_{\mathrm{th}}(x)\end{array}$ & $\begin{array}{l}\text { Photon } \\
\text { Correction } \\
\text { Factor } \\
\text { fy }\end{array}$ & $\begin{array}{c}\text { Backscattering } \\
\text { Correction } \\
\text { Factor } \\
\text { Due to Support } \\
{ }^{2} \text { bs } \\
\end{array}$ & $\begin{array}{c}\text { Computed Thermal } \\
\text { Specific Activity } \\
\text { Corrected for } \\
\text { Photon and Support } \\
\text { Contributions } \\
\text { Of f }\end{array}$ & $\begin{array}{c}\text { Self-Absorption } \\
\text { and } \\
\text { Seli-Siattering } \\
\text { Correction } \\
\text { Factors } \\
\text { f }\end{array}$ \\
\hline 0 & & 2.385 & 0.5609 & 1.00 & & & & $851 *$ & 1.00 \\
\hline 0.0340 & 1545 & 2.385 & $0.560)$ & 1.00 & 807 & 1.0245 & 1.00 & 846 & 0.994 \\
\hline 0.0367 & 1551 & 2.385 & $0.560^{\circ}$ & 1.00 & 870 & 1.0245 & 1.00 & 849 & 0.997 \\
\hline 0.0827 & 1484 & 2.405 & 0.5646 & 1.00 & 838 & 1.0245 & 1.00 & 818 & 0.961 \\
\hline 0.325 & 1433 & 2.445 & 0.5718 & 1.00 & 822 & 1.0242 & 1.021 & 786 & 0.922 \\
\hline 1.30 & 1348 & 2.57 & 0.5426 & 0.996 & 802 & 1.024 & 1.018 & .69 & 0.904 \\
\hline 2.1 & 1300 & 2.72 & 0.6153 & 0.993 & 841 & 1.0237 & 1.014 & 810 & 0.952 \\
\hline 3.074 & 1403 & 2.80 & 0.0263 & 0.990 & 887 & 1.01 & 1.023 & 858 & 1.01 \\
\hline 8.86 & 1441 & 3.42 & 0.6944 & 0.975 & 1025 & 1.022 & 1.01 & 1003 & 1.18 \\
\hline 10.819 & 1467 & 3.60 & 0.7098 & 0.9086 & 1075 & 1.022 & 1.00 & 1052 & 1.24 \\
\hline 19384 & 1318 & 4.30 & 0.7574 & 0.951 & 1050 & 1.023 & 1.00 & 1027 & 1.21 \\
\hline 27.408 & 1264 & 4.89 & 0.7869 & 0.936 & 1062 & 1.023 & 1.00 & 1038 & 1.22 \\
\hline 36.558 & 1121 & 5.40 & 0.8073 & 0.922 & 981 & 1.024 & 1.00 & 958 & 1.13 \\
\hline 55.492 & 929 & 5.98 & 0.8261 & 0.895 & 857 & 1.027 & 1.00 & 835 & 0.98 \\
\hline 69.014 & 803 & 6.16 & 0.8312 & 0.877 & 780 & 1.027 & 1.00 & 758 & 0.89 \\
\hline 85.06 & 691 & 6.25 & 0.8337 & 0.858 & 671 & 1.033 & 1.00 & 650 & 0.76 \\
\hline 99.59 & 613 & 6.27 & 0.8342 & 0.840 & 609 & 1.036 & 1.00 & 588 & 0.69 \\
\hline
\end{tabular}

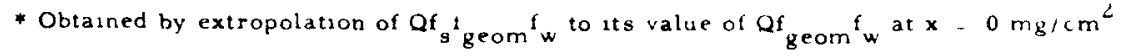


DATA TABLE B-IV

GM DETECTOR WITH THICK SILVER BACKING

\begin{tabular}{|c|c|c|c|}
\hline $\begin{array}{c}\text { Weight } \\
(\mathrm{mg}) \\
\mathbf{x}\end{array}$ & $\begin{array}{c}\text { Total } \\
\text { Specific } \\
\text { Activity } \\
\mathbf{A}(\mathbf{x})\end{array}$ & $\begin{array}{c}\text { Computed Thermal } \\
\text { Specific Activity } \\
A_{\text {th }}(x)=Q_{\text {geom }} f_{w}\left(f_{s} f_{b s}{ }^{f} \gamma\right)^{*}\end{array}$ & $\begin{array}{l}\text { Correction Factor for } \\
\text { Self-Absorption and } \\
\text { Self-Scattering, Infinite } \\
\text { Silver Backscatterer and } \\
\text { Photons } \\
\left(f_{s} \cdot f_{b s} \cdot f_{y}\right)^{*}\end{array}$ \\
\hline 0.0 & & 1458 & 1.71 \\
\hline 0.0346 & 2627 & 1469 & 1.73 \\
\hline 0.0367 & 2562 & 1432 & 1.68 \\
\hline 0.0827 & 2562 & 1447 & 1.70 \\
\hline 0.325 & 2433 & 1394 & 1.64 \\
\hline 1.3 & 2132 & 1268 & 1.49 \\
\hline 2.1 & 2099 & 1301 & 1.53 \\
\hline 3.074 & 2121 & 1341 & 1.56 \\
\hline 8.86 & 1988 & 1415 & 1.66 \\
\hline 10.819 & 1941 & 1423 & 1.67 \\
\hline 19.384 & 1627 & 1295 & 1.52 \\
\hline 27.408 & 1468 & 1234 & 1.45 \\
\hline 36.558 & 1276 & 1117 & 1.31 \\
\hline 55.492 & 1015 & 936 & 1.10 \\
\hline 69.014 & 889 & 843 & 0.97 \\
\hline 85.06 & 741 & 720 & 0.846 \\
\hline 99.58 & 642 & 638 & 0.75 \\
\hline
\end{tabular}

* Corrected by use of Eq. (2) with some values for $R(x)$ and $a(x)$ as in Table B-I. * Obtained by dividing column 3 by Qf ${ }_{\text {geom }}{ }^{f}$ from Table B-III. 


\section{REFERENCES}

1. D. W. Engelkeimeir, et al. "Radiochemical Studies: The Fission Products," National Nuclear Energy Series, IV-9, (McGraw-Hill Book Co., Inc., New York, 1951), p. 56.

2. L. R. Zumwalt, "Absolute Beta Counting Using End-Window Geiger-Mueller Counters and Experimental Data on Beta-Particle Scattering Effects," AECU $-567,1950$.

3. Nuclear Science Series, Conference on Absolute Beta Counting, Preliminary Report \#8, 1950.

4. W. E. Nervik and P. C. Stevenson, Nucleonics 10, No. 3, 18 (1952).

5. R. G. Baker and L. Katz, Nucleonics 11, No. 2, 14 (1953).

6. C. H. Collie, P.F.D. Shaw, and H. J. Gale, Proc. Phys. Soc. (London) A63, 282 (1950).

7. S. D. Warshaw and S. K. Allison, Rev. Mod. Phys. 25, 789 (1953).

8. P. Gilbert, "Flame Photometer Determination of Thicknesses of Thin Indium Foils," unpublished data.

9. W. Von Bothe, Zeits f. Physik, 120, 437 (1943).

10. H. Slatis and S. J. du Toit, et al., Phys. Rev., 78, 498 (1950).

11. L. Seren, et al., Phys. Rev., 72, 888 (1947).

12. S. H. Fitch and J. E. Drummond, Livermore Research Laboratory, Report No. 95, February, 1954. 